\section{Estudo \\ Ecidebate}

em Testão

Plamejamento
Revista Estudo \& Debate, Lajeado, v. 25, n. 1, 2018. ISSN 1983-036X

DOI: http://dx.doi.org/10.22410/issn.1983-036X.v25i1a2018.1641

\title{
ENERGIA EÓLICA NO BRASIL: OPORTUNIDADES E LIMITAÇÓES PARA O DESENVOLVIMENTO SUSTENTÁVEL
}

\author{
Elaine Carvalho de Lima ${ }^{1}$, Isabela Amâncio Santos², Luzélia Calegari Santos Moizinho ${ }^{3}$
}

Resumo: Ao longo dos últimos anos, a expansão da energia eólica no território brasileiro emerge como uma alternativa para diversificar a matriz energética do país e gerar uma fonte de energia mais limpa. Nesse sentido, o presente trabalho busca analisar o contexto atual da produção de energia eólica no Brasil, ressaltando elementos da sustentabilidade presentes nessa fonte energética. Em termos metodológicos, foi realizada uma revisão da literatura sobre a temática de estudo, especialmente no que diz respeito a importância da expansão da energia eólica no Brasil e seus rebatimentos nos desafios para a sustentabilidade. Além disso, foi feita uma pesquisa documental e levantamento de dados das principais instituiçôes relacionadas ao setor. Os resultados mostraram que a energia eólica está em pleno desenvolvimento no território brasileiro, em decorrência da implantação das políticas públicas e incentivos, o que poder ser constatado pelas melhorias constantes na cadeia produtiva desse setor.

Palavras-chave: Energia eólica; Sustentabilidade; Políticas Públicas

\section{WIND ENERGY IN BRAZIL: OPPORTUNITIES AND LIMITATIONS FOR SUSTAINABLE DEVELOPMENT}

\begin{abstract}
Over the last few years, the expansion of wind energy in Brazil emerges as an alternative to diversify the country's energy matrix and generate a cleaner energy source. In this sense, the present work seeks to analyze the current context of wind energy production in Brazil, highlighting elements of sustainability present in this energy source. In methodological terms, a review of the literature on the study topic was carried out, especially with regard to the importance of the expansion of wind energy in Brazil and its refocusing on the challenges to sustainability. In addition, a documentary research and data collection of the main institutions related to the sector was done. The results showed that wind energy is in full development in the Brazilian territory, due to the implementation of public policies and incentives, which can be seen by the constant improvements in the productive chain of this sector.
\end{abstract}

Keywords: Wind power; Sustainability; Public policy.

1 Doutoranda em economia pela Universidade Federal de Uberlândia (UFU). Mestre e graduada em economia pela Universidade Federal do Rio Grande do Norte (UFRN).

2 Mestranda em economia pela Universidade Federal de Uberlândia (UFU).

3 Docente do Instituto Federal do Triângulo Mineiro (IFTM) e doutoranda em economia pela Universidade Federal de Uberlândia (UFU). 


\section{INTRODUÇÁO}

A expansão da energia eólica tem sido um dos principais vetores para a diversificação da matriz energética do Brasil. Tal expansão pode representar uma conduta importante na direçáo de atenuar os efeitos das mudanças climáticas e para garantir a segurança energética no futuro.

De acordo com dados da International Energy Agency (2015), há necessidade de que os policy makers ${ }^{4}$ e partes interessadas repensem açôes no âmbito da geração de energia. Nesse sentido, as energias renováveis têm ganhado notoriedade e incentivos mundiais, isso pode ser constatado pelo aumento dos investimentos em energia na maioria dos países. $\mathrm{Na}$ Organização para a Cooperação e Desenvolvimento Econômico (OCDE), o percentual atinge $37 \%$ do crescimento no abastecimento de eletricidade por esse tipo de energia. Além disso, países como a China, Índia, África e países da América Latina têm destinado grandes investimentos para o setor.

No mundo, a energia eólica responde por grande parte do crescimento na geração de energia por fontes renováveis (34\%), seguida por hidrelétricas (30\%) e solar (18\%) (IEA, 2015). Esse destaque da energia renovável também ocorre no Brasil, na repartição de oferta interna da sua matriz de energia elétrica tem destaque a biomassa de cana- de- açúcar com crescimento de $5,1 \%$ de 2014 para 2015 e outras fontes de energia renováveis com 14,9\% de crescimento no mesmo período, sendo que dentre as outras fontes ganha destaque a energia solar com $97 \%$ de crescimento e a energia eólica com 78\% (EMPRESA DE PESQUISA ENERGÉTICA - EPE, 2016).

Nota-se que o aumento da preocupaçáo sobre a segurança energética e os desafios quanto a instabilidade do mercado do petróleo, trazem à tona a problemática em torno da geração de energia. Além disso, o aumento do preço do petróleo e dos derivados, o padrão de consumo atual, que eleva o gasto energético, tem levado alguns países ao redor do mundo a buscar por fontes alternativas de energia e uma menor dependência de fontes não renováveis, como o petróleo, gás e carvão, que comprometem um futuro sustentável (SACHS, 2007).

O Brasil possui um potencial elevado no aproveitamento da energia hidráulica. Entretanto, uma série de problemas surge quando há a implantação de hidrelétricas, o que as tornam não "sustentáveis". Tais como, mudanças de percursos naturais das águas, mudanças de populaçōes ribeirinhas, perda da biodiversidade, emissóes de gases do efeito estufa na decomposiçấo orgânica do reservatório, entre outros. Além disso, a construção das novas hidrelétricas tem sido alvo de grandes polêmicas, especialmente devido os impactos sociais e ambientais (CASTRO, 2010; CASTRO et al., 2010).

Nesse contexto, o Brasil tem expandido a participação da produção da energia eólica na sua matriz energética. De acordo com a Empresa de Pesquisa Energética (EPE), o crescimento da participação da energia eólica esteve também associado a um projeto público e incentivos para essa fonte energética. Destaca-se a criação do Programa de

4 São indivíduos que têm autoridade para definir o quadro de políticas de uma organização. 
Incentivo às Fontes Alternativas de Energia Elétrica (PROINFA), que foi criado em 2002 e foi considerado um passo importante para a sustentabilidade na geração de energia (BEZERRA, SANTOS, 2017).

O presente trabalho busca analisar o contexto atual da produção de energia eólica no Brasil, ressaltando elementos da sustentabilidade presentes nessa fonte energética. Entre as justificativas para escolha do tema, observa-se que a temática tem ganhado novos contornos na discussão mundial. Uma vez que, a introdução de fontes renováveis no abastecimento de energia é uma maneira de gerar um sistema energético compatível com o desenvolvimento sustentável.

\section{PROCEDIMENTOS METODOLÓGICOS}

Em termos metodológicos, foi realizada uma revisão da literatura sobre a temática de estudo, especialmente no que diz respeito à importância da expansão da energia eólica no Brasil desde os anos 2000 à atualidade, para isso foram utilizados artigos de periódicos nacionais e internacionais, dissertaçóes e teses relacionados à temática. Além disso, foi feita uma pesquisa documental em documentos oficiais do governo brasileiro, como leis e decretos, bem como foi realizado um levantamento de dados das principais instituiçóes relacionadas ao setor, entre estas, o Ministério de Minas e Energia, (MME), a Associaçáo Brasileira de Distribuidores de Energia Elétrica (ABRADEE), o Caderno Setorial ETENE, a Revista Brasileira de Energia, a Revista Brasileira de Energias Renováveis, a International Energy Agency (IEA), a Associação Brasileira de Energia Eólica (ABEEólica), a Agência Nacional de Energia Elétrica (ANEEL), a Empresa de Pesquisa Energética (EPE), o Global World Energy Council (GWEC). Essas fontes de dados foram fundamentais para a análise da relação entre o desenvolvimento sustentável e fontes renováveis de energia elétrica, comparação de crescimento da participação da energia eólica dentro da matriz de energia elétrica brasileira relativa à mesma comparação da matriz mundial, características do setor de energia eólica no Brasil e políticas públicas brasileiras para o setor.

\section{RESULTADOS E DISCUSSÓES}

\subsection{Referencial Teórico: Desenvolvimento Sustentável e a Energia Eólica}

O conceito de sustentabilidade, amplamente difundido, embora não seja o único, foi cunhado em 1987 no Relatório Brundtland, intitulado Our Common Future, e define desenvolvimento sustentável como o "desenvolvimento que satisfaz as necessidades presentes, sem comprometer a capacidade das geraçóes futuras de suprir suas próprias necessidades".

Porém, conforme alerta Stahel (1994) esse conceito de sustentabilidade abrange o sentido restrito, pois, mesmo que implicitamente, a definição esteja voltada para "um desenvolvimento capitalista sustentável, ou seja, uma sustentabilidade dentro do quadro institucional de um capitalismo de mercado" corre o sério risco de esvaziar-se comprimindo o perverso papel de legitimizar a expansão do capitalismo. Se por um lado o capitalismo é per si um sistema expansivo, ou seja, com o objetivo de aumentar continuamente o capital, por outro lado o planeta é limitado. Neste sentido, surge a importância do decoupling, que 
se traduz na dissociação (ou desacoplamento) da curva de produção em relação à curva do impacto ambiental.

Conforme indicado pelo relatório da UNEP (2011) o monitoramento e avaliação dos impactos da natureza seja por mudanças na cobertura da terra e extraçáo de recursos, ou por efeitos colaterais não intencionais das atividades econômicas, como emissóes e resíduos, são fundamentais para que se atinja o bem-estar humano e a sustentabilidade no seu sentido amplo, o que inclui dimensóes além das ecológicas, tais como econômica, cultural e social. Assim, o enfoque na dissociação requer atenção tanto à quantidade de uso de recursos ligada à atividade econômica quanto aos impactos ambientais associados a esse uso de recursos em todos os estágios do ciclo de vida, de forma a prevenir a interrupçáo dos serviços ecossistêmicos essenciais ao bem-estar humano.

Uma análise mais ampla quanto à relação entre os serviços dos ecossistemas e o bem-estar humano sinaliza que "o duplo desafio da sociedade é reter e sustentar um nível suficiente de serviços dos ecossistemas de maneira que contribua para o fortalecimento do bem-estar humano e para a redução da pobreza” (CONSELHO DE AVALIAÇÃO ECOSSISTÊMICA DO MILÊNIO, 2005, p. 137).

Assim, a riqueza de uma nação não pode ser medida sem que o capital natural seja considerado e conforme alerta o Conselho de Avaliação Ecossistêmica do Milênio (2005, p. 67) a "degradação contínua dos ecossistemas mundiais não é inevitável nem justificável," haja vista a gama de instrumentos, conhecimento e tecnologias disponíveis que podem reduzir e reverter muitos dos impactos ambientais causados pela exploração econômica.

Um desses exemplos de tecnologia disponível diz respeito às fontes energéticas. Conforme Stahel (1994, p. 67):

[...] a sociedade industrial contemporânea ainda está baseada no estoque aprisionado de baixa entropia encontrado nas fontes ditas não-renováveis de energia, e não no fluxo contínuo de baixa entropia que nos vem com a energia solar e as formas de energia dela decorrentes (energia eólica, energia hidroelétrica etc.). Além de este processo alterar profundamente diversos ciclos biosféricos, em particular o ciclo do carbono (liberando-se quantidades fantásticas de carbono na atmosfera que antes estavam aprisionadas em cadeias orgânicas no petróleo, carvão, florestas etc., sendo o problema do efeito estufa apenas a sua manifestação mais dramática), tal processo é visivelmente insustentável do ponto de vista energético.

Santos, Filho e Barros (2015) salientam que os planos do uso de energia renovável se diferenciam em cada país, mas de modo geral deve incluir no mínimo, a utilização de: energia eólica, energia geotérmica, energia solar (ou fotovoltaica e térmica), hidroeletricidade e biomassa e biogás.

Do mesmo modo Ringer (2014), destaca a importância das energias renováveis para a garantia da sustentabilidade. Entre os diferentes parâmetros a serem considerados em um programa bem sucedido de desenvolvimento sustentável, destacam-se a educação ambiental, estratégias e promoção de energias renováveis e financiamento e desenvolvimento de ferramentas de monitoramento e avaliação. 
Dincer e Rosen (2013) explicam que a energia eólica é renovável diariamente pela influência do sol. O calor do sol impulsiona os ventos, cuja energia, é capturada com turbinas eólicas e a energia acumulada pode ser transportada por longas distâncias. Segundo os autores é a energia mais facilmente renovável e com menores impactos ambientais.

No estudo de Ringer (2014) é salientado que os cálculos monetários para análise da melhor matriz energética nem sempre consideram todos os impactos ambientais e sociais. Como exemplo não são incluídos os custos externos de produção (como poluição do ar, danos a longo prazo para a saúde, limpeza de derramamento de óleo, saúde ocupacional de trabalhadores na mineração, danos causados a construçóes, agricultura, pesca e aos ecossistemas).

Ringer (2014) apresenta os impactos sociais e ambientais da energia eólica, ressaltando como positivo: i. a geração de empregos de forma geral, com características estáveis e qualificada; ii. menor emissão de gases de efeito estufa dentre as outras fontes de energia; iii. menor impacto pelo uso da área geográfica, podendo ser compartilhada com agricultura e pastagens; iv. menor consumo de água. Como impactos negativos destacamse: i. possibilidade de intermitência, caso a análise das condiçóes de ventos não sejam satisfatórias; ii. impactos na vida selvagem, principalmente a morte de aves migratórias; iii. impactos sonoro e iv. impacto visual. Conforme alerta a autora, tais impactos podem ser minimizados com a avaliação prévia dos locais de instalação dos parques eólicos.

\subsection{Panorama da Energia Eólica no mundo e Brasil}

A energia eólica surge como fonte viável para produção de energia a partir dos anos de 1970 quando o mundo passa por uma crise econômica decorrente da queda na oferta do petróleo, principal insumo energético mundial. Dessa forma, diversos países buscaram formas alternativas de produção de energia. Ao longo da década, os preços do barril de petróleo aumentaram de forma expressiva, em 1972 o barril era cotado a US\$ 2,00 e no final de 1973 chegou a US\$10,00. Após cinco anos de relativa estabilidade de preço, houve um novo choque, que elevou o preço para US\$35,00 em 1979 (FRATE, 2006).

Nesse contexto, de alta volatilidade do petróleo e de incertezas dos preços de oferta, diversos países, principalmente europeus e Estados Unidos, buscaram nas energias renováveis uma alternativa a esse quadro. Assim, a dependência do petróleo e a náo disponibilidade de outros recursos naturais para geração de energia, fizeram com que esses países investissem em outras fontes de energia, principalmente no setor eólico, para garantir o suprimento e reduzir a dependência do petróleo (DUTRA, 2001).

Conforme Dutra (2001), países como Dinamarca, Alemanha e Estados Unidos passaram a investir em programas de Pesquisa e Desenvolvimento (P\&D) com objetivo de desenvolver turbinas eólicas visando a geraçáo de eletricidade, bem como introduziram políticas públicas de incentivo para expandir o mercado, tais como, subsídios e leis federais que garantiam a compra da energia produzida a partir da fonte eólica. Dessa forma, houve o acúmulo de conhecimento e aprendizagem sobre setor, que possibilitou o desenvolvimento industrial do setor. 
Estudos recentes objetivam analisar a evolução das tendências do setor e as possibilidades de se alcançar as metas para a matriz de energia estabelecida para os próximos anos. Enquadra-se nestes estudos o trabalho de González e Lacal-Arántegui (2016) que estabeleceram um quadro regulatório para os países membro da União Europeia no que tange a aspectos de esquemas de suporte, questóes de rede elétrica e barreiras potenciais para implantação de energia eólica. Os autores concluem que em relação às questóes da rede, é uma prática comum que os novos geradores eólicos suportem apenas os custos de extensão da rede para o ponto de conexão mais próximo e enfatizam a necessidade de parcerias e apoio financeiro para expansão de projetos de energia eólica, uma vez que a tecnologia utilizada demanda altos investimentos. Neste cenário, a estabilidade do quadro regulatório é uma das preocupaçóes mais importantes para os investidores e a expansão real da quantidade de energia eólica fornecida está diretamente associada à evolução dos quadros regulatórios.

O estudo de Bean, Blazquez e Nezamuddin (2017) analisa quais seriam, dentre três diferentes tipos de políticas de incentivo à expansão de instalaçôes de energia eólica, os mais apropriados a partir de uma abordagem de custo-benefício. Utilizando-se de uma amostra de mais de 300 empresas espanholas produtoras de energia eólica, durante o período de 2006 a 2013, os autores avaliaram três tipos de subsídio: o primeiro do tipo feed-in tariff (FIT), ou contratos de oferta padrão, o segundo do tipo feed-in premium (FIP), ou preço acima do mercado e por último créditos de investimento (IC). Os autores identificaram que a opção mais rentável, pela perspectiva de investimentos públicos, é a política de crédito de investimentos, dada a intensidade de capital da tecnologia eólica. Os resultados evidenciam que um crédito de investimento produz resultados semelhantes a outras opçóes de política, como contratos de oferta padrão e prêmios, mas a um custo mais barato e com menor risco para os contribuintes ou consumidores de eletricidade porque os custos não flutuam com os preços do mercado de eletricidade. Na perspectiva dos investidores privados, os créditos de investimento são a forma mais econômica de promover a energia renovável, mas levam ao menor retorno do capital empregado para esses investidores e pelo contrário, os contratos de oferta padrão fornecem uma receita garantida aos investidores, mas o custo total da política é o mais alto para os consumidores.

Outro fator importante a ser considerado é a relação do aumento dos investimentos em energias renováveis com a questão ambiental. Nota-se que os desastres ambientais são temas predominantes e recorrentes na atualidade, no qual há debates e questionamentos sobre o problema de conciliar o desenvolvimento socioeconômico com a preservação do meio ambiente (FRATE, 2006; DUTRA, 2001).

Atualmente, o mercado mundial da produção de energia eólica está em plena ascensão, apresentando um quadro regular de investimentos, conforme aponta o anual da GLOBAL WORLD ENERGY COUNCIL (GWEC). Em 2015 foram US\$ 329 bilhóes de dólares de investimentos em energias renováveis, $4 \%$ a mais do que em 2014 . Em termos de produção, os últimos dados da GWEC mostram que a cada ano a energia eólica apresenta expansão em capacidade instalada. No gráfico 1, observa-se que o mercado tem um comportamento de crescimento ao decorrer dos anos. Por exemplo, no início dos anos 2000 apresentava-se uma capacidade mundial instalada de 17.400 Megawatts (MW), já no final de 2015 essa 
capacidade chegou a 432.883 MW, 24.000\% de crescimento nos últimos 15 anos (GWEC, 2015).

Gráfico 1 - Evolução da Capacidade Eólica Instalada no Mundo em MW (2000-2015)

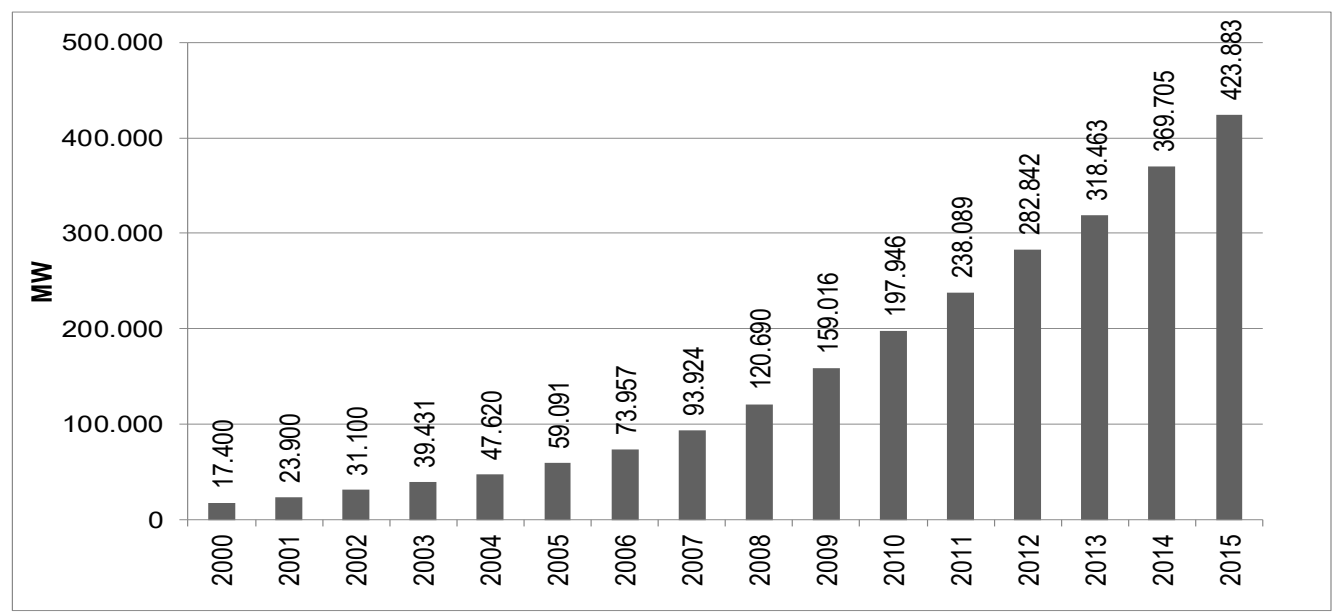

Fonte: Dados da GWEC (2015).

Tal aspecto pode contribuir para segurança na oferta de energia e amenizar impactos ambientais nas matrizes elétricas de diversos países. Além disso, os países com grandes economias e dependentes de combustíveis fósseis são os que mais adicionaram parques eólicos em suas matrizes. Assim, no ranking dos 10 maiores produtores de energia eólica estão presentes àqueles com grande demanda por energia (GRÁFICO 2).

Gráfico 2 - Os 10 países com maior capacidade instalada em energia eólica (2015)

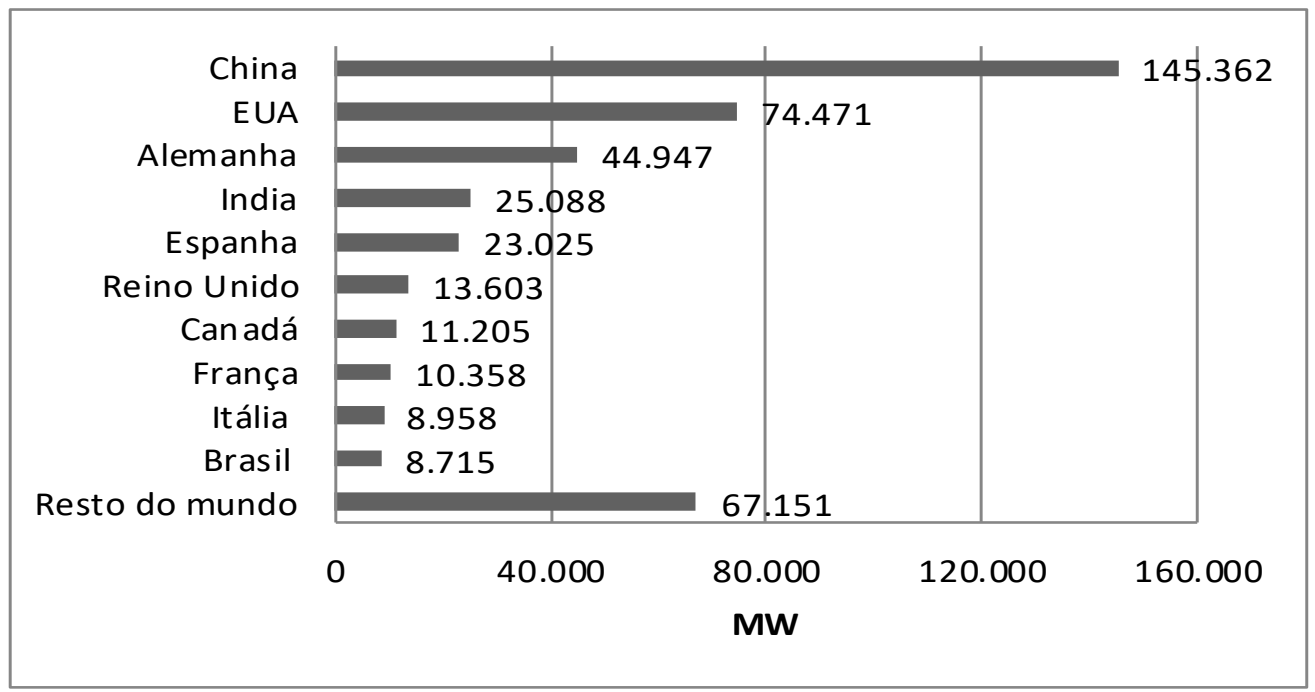

Fonte: GWEC (2015). 
De acordo com a GWEC (2015), os três primeiros colocados em acumulação de capacidade eólica instalada no mundo são responsáveis por $61 \%$ do total mundial. Pelo gráfico 2, observa-se que o mercado mundial é liderado pela China tanto em capacidade acumulada (são $145.362 \mathrm{MW}$ ou $33 \%$ do total) quanto em capacidade adicional. Em 2015, o país adicionou $30.753 \mathrm{MW}$, sendo responsável por $48 \%$ de acréscimo do total mundial em comparação ao ano anterior, 2014. Em seguida vem os Estados Unidos, com uma capacidade instalada acumulada de $74.471 \mathrm{MW}$ ou $17.2 \%$ do total mundial, tendo adicionado 8.598 MW em 2015. Por fim, a Alemanha com 44.947 MW de capacidade acumulada (10.4\% do total mundial), que em 2015 adicionou 6.013 MW de capacidade (9.5\% do total adicionado) em relação ao ano anterior (GWEC, 2015).

\subsubsection{Energia Eólica no Território Brasileiro}

No caso do mercado eólico brasileiro, o país vem apresentando bons resultados nos últimos anos, tanto em capacidade acumulada de energia eólica quanto em acréscimo de capacidade. Uma das variáveis fundamentais na geração de energia elétrica por fonte eólica é a quantidade e qualidade dos ventos. Nesse quesito, o Brasil tem um dos melhores recursos eólicos do mundo. Segundo dados do Atlas do Potencial Eólico Brasileiro, Amarante et al. (2013), o potencial eólico brasileiro pode chegar a aproximadamente $880 \mathrm{GW}$ com máquinas de 100 metros, sendo que $522 \mathrm{GW}$ são considerados tecnicamente viáveis. Salienta-se que a Região Nordeste possui as melhores condiçóes de aproveitamento do vento para a geração de energia eólica no país.

Bezerra e Santos (2017) destacam que até recentemente, a energia elétrica produzida na Região Nordeste era oriunda da fonte hidráulica, notadamente do rio São Francisco. Dessa forma, a Companhia Hidrelétrica do São Francisco (Chesf) possui uma grande importância sendo a principal empresa na geração de energia elétrica para o Nordeste. Os autores também mostram que esse quadro tem sido alterado nos últimos anos, especialmente a partir de 2013, com o aumento da capacidade instalada na geração de energia eólica.

A energia eólica foi introduzida na matriz elétrica nacional, comercialmente, pós racionamento de energia elétrica de 2001, que revelou um grave problema estrutural, no qual a oferta de eletricidade por hidrelétricas não atendia totalmente a demanda. Dessa forma, houve a necessidade de se repensar o planejamento do setor elétrico, onde o Estado foi fundamental para desenvolver políticas de incentivos, financiamentos e investimentos, além de buscar parcerias estratégicas com o setor privado (GAVINO, 2011; DUTRA, 2001).

Neste sentido, o Estado brasileiro adota duas políticas fundamentais para incentivar o desenvolvimento de fontes alternativas de energia no país. Desenvolveu o Programa de Incentivo às Fontes Alternativas de Energia Elétrica (PROINFA) em 2004 e, posteriormente, os Leilóes de energia.

Em termos de produção, o mercado eólico brasileiro está em plena expansão. Apesar do Brasil ser o $10^{\circ}$ colocado no ranking mundial em capacidade eólica acumulada, o país adicionou, em 2015, 2.754 MW de capacidade instalada (em relação a 2014), foi o $4^{\circ}$ 
no mundo, ficando atrás apenas da China, Estados Unidos e Alemanha (GWEC, 2015; ABEEÓLICA, 2015).

O Gráfico 3, a seguir, ilustra a evolução do setor eólico em termos de capacidade instalada. A produção do país saltou de 29 MW em 2005 para 8.715 MW em 2015, potencial suficiente para atender a demanda por energia elétrica da região Sul do país. (ABEEÓLICA, 2016; GWEC, 2015). Nesse sentido, essa expansão gera duas consequências de cunho econômico: a primeira é a expansão da oferta de energia no país e aumento da segurança energética; a segunda refere-se aos ganhos de escala, uma vez que, em decorrência do aumento da produçáo há uma tendência de diminuiçáo dos custos médios de produçáo da energia por MW.

Gráfico 3- Evolução da capacidade instalada de energia eólica Brasil (2005-2015)

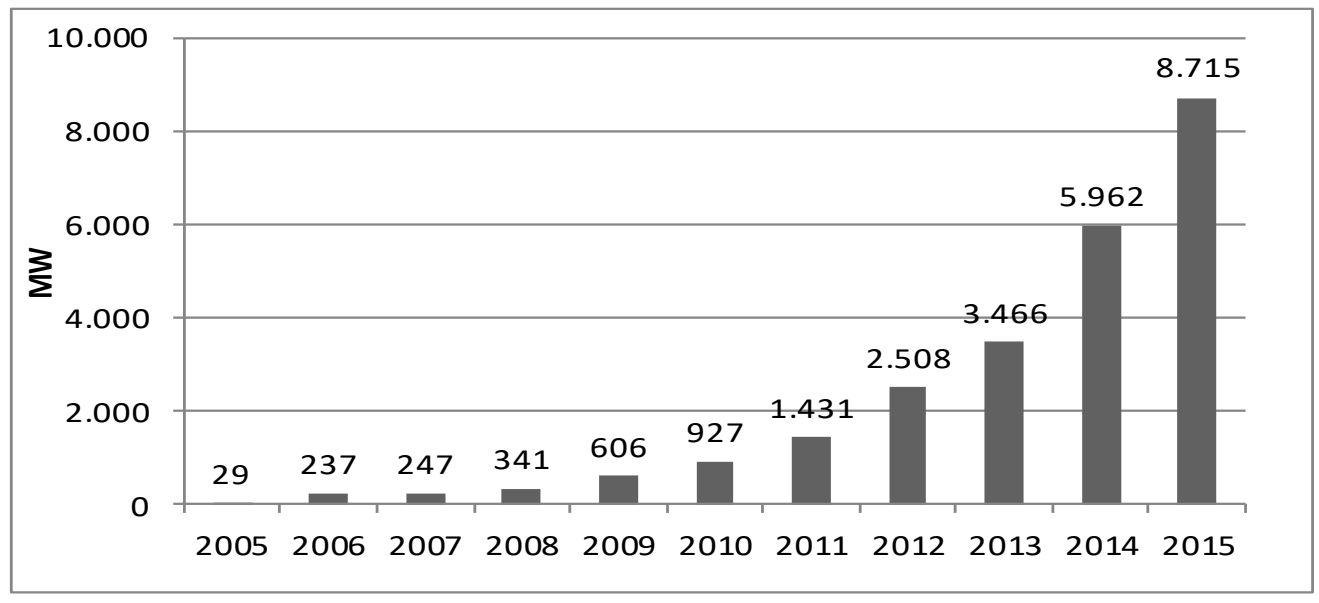

Fonte: GWEC (2015).

Com essa expansão, a fonte eólica é que mais cresce em termos de participação na matriz elétrica nacional. Em 2015, considerando-se todas as fontes energéticas, foram instalados 7.000 MW de capacidade na matriz elétrica, sendo que a energia eólica liderou em participação, gerando $39 \%$ do total. Além disso, atualmente são $6.2 \%$ da demanda nacional por energia elétrica atendido pela energia eólica, com potencial de crescimento em virtude dos contratos já firmados nos leilóes e no mercado livre (ABEEÓLICA, 2015; GWEC, 2015).

No ano de 2016, a repartição da oferta interna de energia elétrica no Brasil foi de $41,2 \%$ de fontes renováveis e $58,8 \%$ de fontes não renováveis. Dentre as fontes não renováveis estão $37,3 \%$ para petróleo e derivados, $13,7 \%$ de gás natural, 5,9\% de carvão mineral, $1,3 \%$ de urânio e $0,6 \%$ de outras fontes. Dentre as fontes renováveis estão 16,9\% de biomassa da cana, 11,3\% hidráulica, 8,2\% de lenha e carvão vegetal e 4,7\% de lixívia e outras fontes. A repartição de lixívia e outras fontes renováveis tem a fonte de energia elétrica eólica com 13,1\% de participação, representando um crescimento de $78 \%$ de participação em relação ao ano anterior. (EMPRESA DE PESQUISA ENERGÉTICA - EPE, 2016) 
Ademais, informaçôes obtidas do sítio da ABEEÓLICA afirmam que o Brasil alcançou a marca de $10 \mathrm{GW}$ de capacidade eólica instalada no final de 2016, com mais de 400 parques eólicos instalados no território. Somente de investimentos das empresas da cadeia produtiva do setor foram $\mathrm{R} \$ 48$ bilhóes entre 2011 a 2016, com $80 \%$ da cadeia produtiva nacionalizada. Em termos de postos de trabalhos, a energia eólica gerou mais 41 mil empregos (ABEEÓLICA, 2016).

Numa análise mais focalizada, a região Nordeste é a grande impulsionadora do mercado eólico brasileiro. Devido sua abundância em bons ventos, a região tem atraído grandes investimentos, tanto para produçáo de energia quanto para o desenvolvimento do setor industrial (MACEDO, 2015; OLIVEIRA NETO, 2016).

Bezerra e Santos (2017) enfatizam que grande parte dos projetos participantes dos leilóes de energia da Agência Nacional de Energia Elétrica (ANEEL) está no Nordeste. Por tal motivo, alguns fabricantes de aerogeradores ${ }^{5}$ se instalaram na região, bem como inúmeros fabricantes de demais componentes (torres, pás, etc.). Entre os principais fabricantes, destacam-se: Acciona Windpower, Aeris, Gamesa, Tecsis, Vestas, Wobben/ Enercon.

Neste sentido, quando se observa os dados de 2015, os resultados mostram que o Nordeste possui $80 \%$ da capacidade eólica instalada, dos quais de um total de $8.715 \mathrm{MW}$ a região possui $6.888 \mathrm{MW}$. Alguns estados da região se destacam a nível nacional com grande capacidade eólica instalada. Entre estes, o estado do Rio Grande do Norte lidera em capacidade instalada com $2.779 \mathrm{MW}$, seguido por Bahia e Ceará com 1.618 MW e 1.304 MW, respectivamente (Gráfico 4). Estes estados lideram o ranking, principalmente, por terem excelentes ventos, concentrando os empreendimentos eólicos no Brasil e Nordeste. Contudo, outros estados da região vêm quebrando essa hegemonia, permitindo uma desconcentraçấo dos empreendimentos eólicos. Destacam-se, o Piauí e Pernambuco, que vêm sendo contemplados nos leilóes de energia eólica. Em 2015 o Piauí entregou 617 MW de capacidade e o Pernambuco 272 MW (ABEEÓLICA, 2015).

5 Também conhecido como turbina eólica, trata-se de um equipamento que converte a energia cinética do vento em energia elétrica. 
Gráfico 4 - Capacidade eólica instalada por estado em 2015

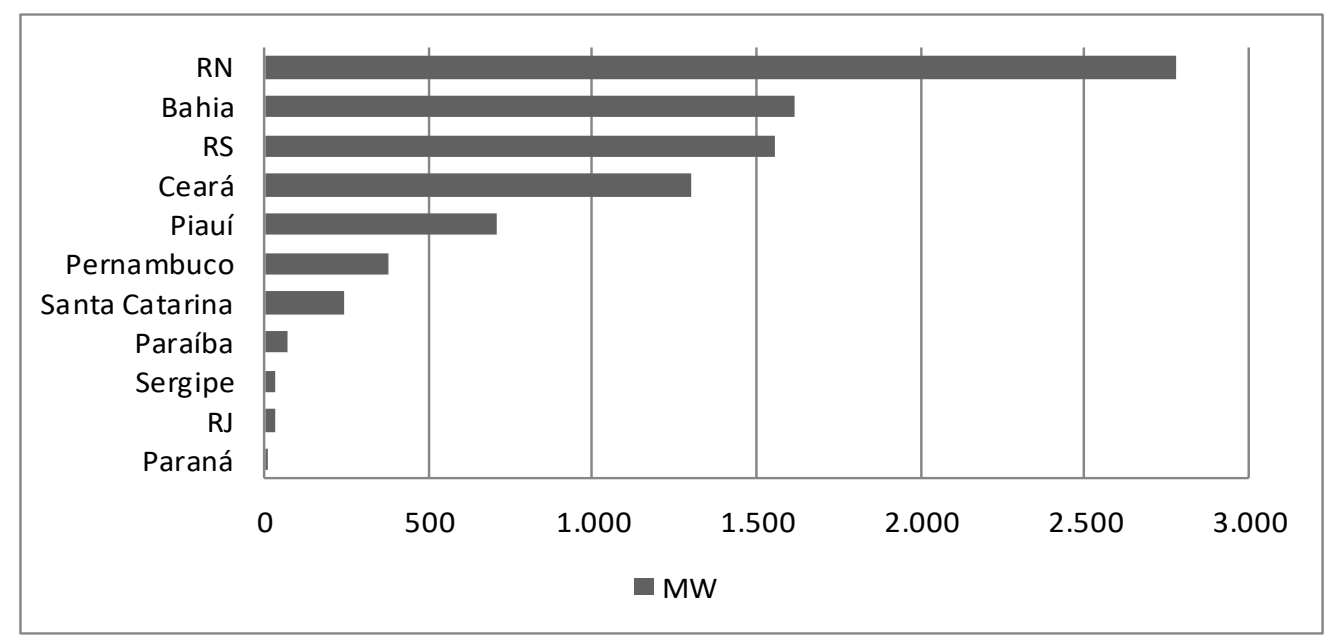

Fonte: GWEC, 2015.

Essa tendência de desconcentração dos investimentos e, consequentemente, dos parques eólicos, tem a relação direta com o que é oferecido pelos estados em termos de infraestrutura e políticas públicas. Neste sentido, Macedo (2015) revela que as políticas públicas são um diferencial para o sucesso da energia eólica no Brasil. A autora argumenta que essas políticas, por outro lado, tem “(...) um aspecto importante que é o desenvolvimento da energia elétrica nos estados, configurando um processo de valorização dos espaços” (MACEDO, 2015, p. 265).

Dessa forma, estados que sempre estiveram na dianteira da produção de energia eólica devido a abundância em recursos, não garantem a vinda de empreendimentos contando apenas com essa variável. Conforme Macedo (2015, p. 317) adverte, "não basta ter vento. É preciso, adicionalmente, fomentar o encadeamento produtivo com investimento em infraestrutura de transmissão e de logística, e com incentivos financeiros”.

De acordo com a ABEEÓLICA (2015), o Brasil tem apresentado uma cadeia produtiva do setor com diversificação e grande potencial de crescimento no território brasileiro. A indústria eólica tem acumulado conhecimento e vem se expandindo no país, incorporando três importantes externalidades positivas ou benefícios: a primeira é o aumento da capacidade produtiva pela indústria do setor eólico; a segunda é incremento a demanda agregada, pois haverá mais demanda por mão de obra qualificada, compra de equipamentos e insumos para o setor, materiais, etc. E, por fim, a expansão da capacidade eólica ajuda a aumentar a oferta de energia elétrica.

Nesse sentido, a próxima seção trará uma breve revisão das principais políticas públicas do setor. Em certa medida, a literatura evidencia que três políticas foram fundamentais para o fomento do mercado eólico: o PROINFA, que é tido como marco inicial de incentivo à produção de energias renováveis; os leilóes, implementados em 2009, que possibilitaram 
investimentos nos empreendimentos eólicos. Por fim, as linhas de financiamento para suprimento de máquinas e equipamentos pelo BNDES.

\subsection{Energia Eólica e as Políticas Públicas para o setor}

As políticas públicas para o setor de energia eólica são essenciais para a diversificação da matriz elétrica, desconcentração dos investimentos em fontes de energia alternativas, expansão da malha de energia eólica e ampliação da oferta desta. Isso porque, por meio delas, se constitui o incentivo da iniciativa privada à empreendimentos de grande porte como é o caso da energia eólica.

O Ministério de Minas e Energia (MME) se dedica a projetos que tem como destaque no setor de energia o "Plano Nacional de Mineração 2030", o recolhimento para pesquisa e desenvolvimento, o horário brasileiro de verão, o zoneamento nacional de recursos de óleo e gás e PEMAT. O "Plano Nacional de Mineração 2030" tem como base a governança pública, agregação de valor e sustentabilidade e, por meio desta, pretende nortear políticas públicas para que o setor mineral seja um alicerce para o desenvolvimento sustentável do Brasil nos próximos 20 anos (BRASIL, 2011).

O recolhimento para pesquisa e desenvolvimento é baseado na lei no 9.991 , de 24 de julho de 2000, que estipula a obrigatoriedade de que as empresas de energia destinem parte de sua receita líquida para pesquisa e desenvolvimento, sendo destinada para o Fundo Nacional de Desenvolvimento Científico e Tecnológico (FNDCT), Agência Nacional de Energia Elétrica (ANEEL) e Ministério de Minas e Energia (MME) (BRASIL, 2000). O horário brasileiro de verão tem como intuito o melhor aproveitamento da luz natural em relação à artificial, segundo o Ministério de Minas e Energia: “Ocorre um 'achatamento' da curva de consumo. Dessa forma, consegue-se um menor carregamento de energia nas linhas de transmissão, nas subestações, e nos sistemas de distribuição" (BASILIO, 2017).

O zoneamento nacional de recursos de óleo e gás é uma base de dados de georreferência que tem o intuito de direcionar projetos e políticas públicas do setor de óleo e gás para melhor aproveitamento desses recursos. O PEMAT (Programa de Expansão da Malha de Transporte Dutoviário) é um programa que visa a construção e ampliação de gasodutos composto por seminário de lançamento, coleta de informaçáo e elaboração de versão preliminar do plano, publicação da portaria MME no 130, consulta pública do PEMAT, realização de workshop com os principais agentes da indústria, publicação da $1^{a}$ versão do PEMAT e início do ciclo anual (EMPRESA DE PESQUISA ENERGÉTICA EPE, 2014).

Tais aspectos do setor de energia do MME focam na diversificação da matriz energética, melhor aproveitamento dos recursos disponíveis e desenvolvimento aliado à sustentabilidade. No entanto, nenhum destes citados é específico de energia eólica. Algumas das políticas que mais satisfazem esse setor específico são o do PROINFA, os leilóes para investimentos em empreendimentos eólicos e as linhas de financiamento para suprimento de máquinas e equipamentos pelo BNDES.

O PROINFA é um programa que foi criado em 2004 pelo Decreto no 5.025 com o objetivo principal de diversificar a matriz de energia elétrica do Sistema Elétrico Interligado 
Nacional (SIN) com ampliação da matriz de energia eólica, biomassa e pequenas centrais hidrelétricas, de acordo com o artigo $5^{\circ}$ do decreto. Além disso, "O PROINFA também visa reduzir a emissão de gases de efeito estufa, nos termos da Convenção-Quadro das Naçóes Unidas sobre Mudança do Clima, contribuindo para o desenvolvimento sustentável" (BRASIL, 2004b)

O programa é administrado pelo Ministério de Minas e Energia, o qual é responsável pelo planejamento anual dos projetos a serem implementados e pela avaliaçáo de impacto dos projetos já implementados. Enquanto a Eletrobrás assume o papel de celebrar os contratos de compra de energia elétrica de instalaçóes de produção. E, por fim, a Agência Nacional de Energia Elétrica é responsável pela fiscalização técnica dos projetos submetidos ao programa, fiscalização do cumprimento dos critérios propostos pelo decreto em que se baseia o programa e regulação dos procedimentos que compóem a execução dos projetos.

A meta do programa é proporcionar um aumento de capacidade instalada de 3.300 MW (MegaWatts) distribuídos igualmente entre a matriz de energia eólica, biomassa e pequenas centrais hidrelétricas. Uma das exigências do programa é o grau de nacionalização de máquinas e equipamentos e de serviços, o que impacta fortemente na cadeia de fornecimento local e na ampliação do mercado de mão de obra qualificada (DUTRA e SZKLO, 2006).

A previsão inicial do programa para a matriz eólica era a implantação de 54 usinas eólicas com capacidade instalada de 1.422,92 MW. Em 2011, sete anos após o decreto que baseia o programa ser promulgado, 41 usinas eólicas já haviam sido implantadas com capacidade instalada de 963,99 MW.

Segundo informativo do PROINFA (2016), foram contratados 253,55 MW em operação comercial pelo PAC (Programa de Aceleração do Crescimento), o restante do total de 1136,6 MW em construçáo ou em processo de construçáo não iniciada. Destes, há quase totalidade de concentração no Nordeste e Sul com 152,95 MW de operação comercial pelo PAC e o restante do total de $805,58 \mathrm{MW}$ em construção ou em processo de construção não iniciada no nordeste e $159 \mathrm{MW}$ de operaçáo comercial pelo PAC e o restante do total de 454,29 MW em construção ou em processo de construção não iniciada no sul. A exceção à concentração nas regióes Nordeste e Sul do país se deve aos 163,05 MW na região Sudeste, em processo de construção ou construção não iniciada.

Outros estudos mostram a continuidade dessa concentração com 54 projetos selecionados com capacidade de $1423 \mathrm{MW}$, principalmente concentrados na regiáo Nordeste, o que pode ser observado na Tabela 1. 
Tabela 1 - Projetos Eólicos do PROINFA

\begin{tabular}{l|l|c|c}
\hline Regiáo & Estado & Projetos & Potência (MW) \\
\hline \multirow{4}{*}{ Nordeste } & Ceará & 14 & 500,53 \\
\cline { 2 - 4 } & Paraíba & 14 & 60,35 \\
\cline { 2 - 4 } & Pernambuco & 5 & 21,25 \\
\cline { 2 - 4 } & Piauí & 1 & 17,85 \\
\cline { 2 - 4 } & Rio Grande do Norte & 3 & 201,10 \\
\cline { 2 - 4 } & Total & $\mathbf{3 6}$ & $\mathbf{8 0 5 , 5 8}$ \\
\hline \multirow{2}{*}{ Região Sudeste } & Rio de Janeiro & 2 & 163,05 \\
\hline \multirow{2}{*}{ Totáo Sul } & Total & 11 & 163,05 \\
\cline { 2 - 4 } & Santa Catarina & $\mathbf{1 6}$ & $\mathbf{2 2 6 , 7 3}$ \\
\hline & Rio Grande do Sul & 54 & $\mathbf{4 5 4 , 2 9}$ \\
\cline { 2 - 4 } & Total & & 1422,92 \\
\hline
\end{tabular}

Fonte: ELETROBRÁS (2005).

Nesse sentido, o PROINFA foi fundamental para impulsionar o desenvolvimento do setor eólico no Brasil. Dados da ABEEólica (2017) mostram que o setor tem avançado nos últimos anos quanto ao investimento na capacidade instalada e perspectivas de novas instalações de parques eólicos. Em 2017, o país possuía mais de 500 usinas eólicas instaladas, o que representava aproximadamente 6500 aerogeradores instalados e 12,7 GW de capacidade instalada. Nesse contexto, o Brasil está entre os principais países com expansão dessa fonte de energia em sua matriz energética, ocupando a oitava posição no ranking ${ }^{6}$ de países com maior potência eólica instalada em 2017. A Figura 1 ilustra a capacidade instalada e o número de parques eólicos instalados no Brasil.

6 Ranking com os dez países que lideram em capacidade instalada: China, Estados Unidos, Alemanha, Índia, Espanha, Reino Unido, França, Brasil, Canadá, Itália. Ver: http://www.abeeolica.org.br/noticias/brasilsobe-mais-uma-posicao-no-ranking-mundial-de-capacidade-instalada-de-energia-eolica/ 
Figura 1- Número de Parques Eólicos e Capacidade Instalada por Estado em 2017

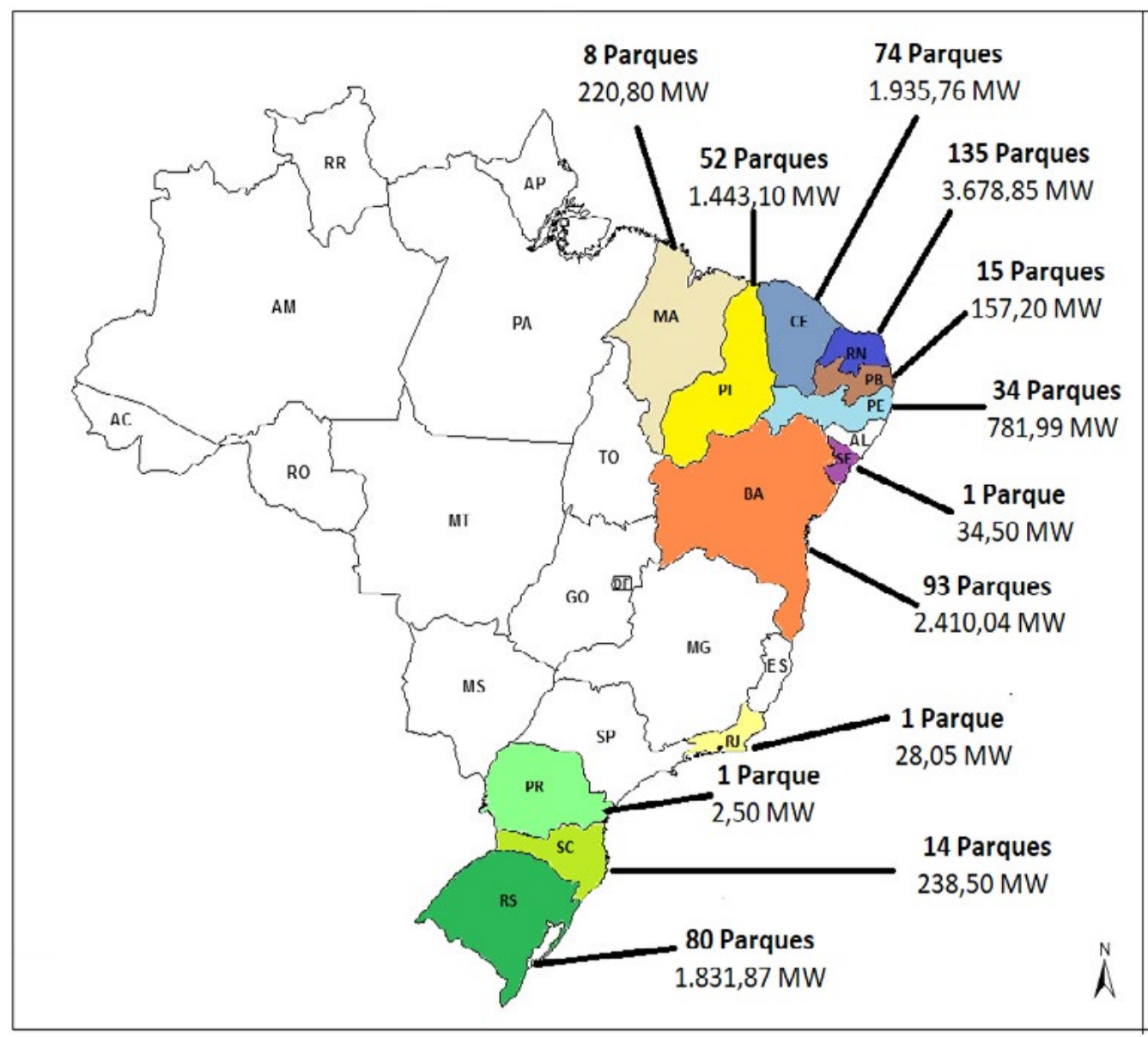

Fonte: Elaboração própria com base na ABEEÓLICA (2018).

Em 2017, o país possuía 508 usinas eólicas com capacidade instalada total de aproximadamente $13 \mathrm{GW}$. Observa-se que a região Nordeste lidera em números de usinas eólicas no país, o estado do Rio Grande do Norte está em primeira posição em capacidade instalada com 3.678,85 MW, seguido pelos estados da Bahia e Ceará, com respectivamente, 2.410,04 MW e 1.935,76MW.

Outra política de incentivo ao setor de energia eólica são os leilóes ${ }^{7}$ para investimento em empreendimentos eólicos, que são realizados com o objetivo de conceder a concessão de novas usinas para o fornecimento de energia adequado com a demanda nacional. Por meio desse processo licitatório, é definida a participação das diferentes fontes de energia na matriz de geração de energia elétrica e, por conseguinte, na qualidade ambiental dessa matriz.

7 Andrade, Oliveira e Oliveira Pinto (2014) apontam que a participação eólica nos leilóes foi um marco para a atração de investidores nacionais e internacionais. 
Os leilóes são conduzidos pela ANEEL (Agência Nacional de Energia Elétrica), que coordena e controla todo o processo, sendo que, há leilóes de empreendimentos novos e existentes, de energia nova e de energia existente. Os leilóes de energia existente dizem respeito à contratação de energia para o curto prazo, normalmente para o ano seguinte, o que implica que a energia seja proveniente de empreendimentos já em operação. Enquanto os leilóes de energia nova dizem respeito à contratação de energia para médios e longos prazos, o que implica que a energia seja proveniente de usinas em projeto ou em construção (BRASIL, 2004a).

Em relação aos leilóes para investimento em empreendimentos eólicos especificamente, o foco no setor eólico depende da chamada do edital de cada leilão. Ou seja, é uma política de incentivo não só ao setor eólico, mas que contempla esse setor em determinadas ocasióes. "Este sistema de leilóes desenvolvido consegue coordenar a expansão do parque gerador e provisionar a alocação da energia gerada por eles de acordo com as demandas das distribuidoras de energia elétrica, verificadas através das projeções de mercado de cada uma delas" (CARNEIRO; CEQUEIRA, 2016, p. 3).

Por fim, as linhas de financiamento para suprimento de máquinas e equipamentos pelo BNDES também são consideradas uma importante política pública de incentivo ao setor eólico, na medida que proporciona subsídio desse setor ao facilitar a aquisição de máquinas e equipamentos para geração e distribuição de energia, sendo que estes são de considerados um investimento de alto valor. As linhas de financiamento específicas para energia eólica, biomassa, cogeração e PCH (Pequena Central Hidrelétrica) tem a participação de até 70\% dos itens financiáveis e o custo de 100\% TJLP (Taxa de Juros de Longo Prazo). Segundo o BNDES (2017a), o objetivo dessas linhas de financiamento do setor eólico é "apoiar empreendimentos que visem à expansão e/ou modernização da infraestrutura de geração de energia do País".

Uma das linhas de financiamento específica para energia eólica é o Fundo Clima para energias renováveis, que tem como objetivo "apoiar investimentos em geração e distribuição local de energia renovável, no desenvolvimento tecnológico e na cadeia produtiva do setor de energias renováveis" (BNDES, 2017b) e como alguns dos empreendimentos apoiavam a implantação de projetos que visem ao desenvolvimento tecnológico do setor de energia eólica.

Dentre os desafios da sociedade contemporânea, garantir o desenvolvimento sustentável se apresenta como uma pressão para todos os países, o que pode ser evidenciado nas recentes convençóes, decretos e diálogos sobre o futuro do planeta.

Um exemplo é o artigo $5^{\circ}$ do decreto 5025, já citado anteriormente, sobre o PROINFA, cujo programa também visa a redução da emissão de gases segundo as normas da Convenção-Quadro das Naçóes Unidas sobre Mudança do Clima (UNFCCC). Essa Convenção-Quadro foi elaborada durante a Conferência das Naçóes Unidas para o Meio Ambiente e o Desenvolvimento, a qual foi realizada no Rio de Janeiro em 1992, a Rio 92. A importância da conferência se traduz na participação de representantes de 179 países que consolidaram uma agenda global em favor do meio ambiente, dessa forma, é um marco para a consolidação do debate do desenvolvimento sustentável a nível global. 
Entre os compromissos assumidos pela Convenção-Quadro, que partem do princípio de proteção ao sistema climático em benefício das geraçôes presentes e futuras, está a implementação de programas nacionais para adaptação a mudança do clima e a promoção e cooperação em pesquisas científicas, tecnológicas, técnicas e socioeconômicas. Diante disso, as políticas públicas brasileiras do setor de energia e, principalmente, do setor de energia eólica refletem as normas estabelecidas não somente pela Convenção-Quadro mas também pela Conferência como um todo.

\section{CONCLUSÓES}

Este trabalho teve como objetivo a análise do contexto atual da produçáo de energia eólica no Brasil destacando elementos de sustentabilidade. Por meio desta análise, foi possível perceber que a energia eólica está em pleno desenvolvimento no território brasileiro, do mesmo modo que sua cadeia produtiva, devido às políticas públicas e incentivos destinados a esse setor.

Foi visto, por meio do panorama da matriz energética do Brasil e do mundo, o crescimento da participação da energia eólica na matriz de energia elétrica em função de sua diversificação. As energias renováveis, como a energia eólica, tem um papel positivo e fundamental em relaçáo às mudanças climáticas e à segurança energética. Dessa forma, se materializam como uma alternativa tecnológica que minimizam o impacto das atividades econômicas na natureza.

As políticas públicas de energia eólica devem contemplar os processos de educação ambiental, estratégias e promoção de energia eólica, financiamento e desenvolvimento de ferramentas de monitoramento e avaliação das próprias políticas em questão. Dentre as políticas públicas destinadas à energia em geral e energia eólica analisadas e citadas no trabalho estão o "Plano Nacional de Mineração 2030", o recolhimento para pesquisa e desenvolvimento pelo Ministério de Minas e Energia, o horário brasileiro de verão, o zoneamento nacional de recursos de óleo e gás, o PEMAT, o PROINFA, os leilóes para investimento em empreendimentos eólicos e a Fundo Clima. Sendo que a energia eólica enquanto objeto de estudo tem destaque por ser mais facilmente renovável e apresentar menos impactos ambientais.

Embora ainda existam áreas de oportunidades para a expansão da energia eólica no Brasil, pode-se avaliar o cenário sob uma perspectiva otimista. Este trabalho evidenciou que o Brasil já apresenta uma cadeia produtiva do setor bastante desenvolvida e diversificada acumulando conhecimento e expandindo gradativamente. Dentre as externalidades positivas geradas, destacam-se: i. o aumento da capacidade produtiva pela indústria do setor eólico; ii. o incremento da demanda agregada, pois exige-se mão de obra qualificada, compra de equipamentos e insumos para o setor; e iii. a expansão da capacidade eólica ajuda a aumentar a oferta de energia elétrica.

Especificamente em relação à política pública do PROINFA, foi identificada com o programa já em execução a necessidade de se introduzir mecanismos de desoneração fiscal aos investimentos eólicos para que o setor de energia eólica mantenha um nível de competitividade diante dos outros setores geradores de energia elétrica. O programa, além de contribuir 
para a diversificação da matriz energética nacional, fomentou a geração de cerca de 150 mil empregos diretos e indiretos e possibilitou a reduçáo de emissóes de gases de efeito estufa em aproximadamente 2,5 milhóes de toneladas de $\mathrm{CO}_{2}$ eq/ano.

Assim, o presente trabalho apresentou como as políticas públicas brasileiras do setor de energia eólica buscam diversificar a matriz energética nacional com o intuito de aumentar o potencial utilizado de energia de fonte renovável para que, desse modo, se aproxime de um desenvolvimento sustentável que permita o crescimento econômico em sinergia com o meio ambiente. É importante destacar que essas políticas públicas se complementam desde linhas de financiamento de investimentos no setor até programas mais articulados como o Proinfa, isto porque é necessário que a atuação dos policy makers seja integrada para que o efeito seja nacional e consistente.

\section{REFERÊNCIAS}

\section{ABEEÓLICA: ASSOCIAÇÃO BRASILEIRA DE ENERGIA EÓLICA Analysis of the regulatory framework for wind power generation in Brazil -summary report.} Disponível em <http://gwec.net/wp-content/uploads/2012/06/Brazil_report_2011.pdf> Acesso em: 9 de dez.

ABEEÓLICA: ASSOCIAÇÃO BRASILEIRA DE ENERGIA EÓLICA. Boletim anual de geração, 2015. Disponível em: http://www.abeeolica.org.br/wp-content/ uploads/2016/08/Abeeolica_BOLETIM-2015_low.pdf. Acesso em: 30 de nov. 2016.

. ASSOCIAÇÃO BRASILEIRA DE ENERGIA EÓLICA. Info vento no 05 :

Dados gerais importantes para o Brasil, 2018. Disponível em: http://www.abeeolica.org. br/wp-content/uploads/2018/01/05_Infovento-online.pdf. Acesso em: 08 de março de 2017.

ABRADEE Associação Brasileira de Distribuidores de Energia Elétrica. Disponível em: http://www.abradee.com.br/setor-eletrico/leiloes-de-energia Acesso em: 10 de dez de 2016.

. Brasil chega à marca de $10 \mathrm{GW}$ de energia eólica em capacidade instalada. Notícia sitio ABEEÓLICA, 06 Dez 2016. Disponível em: http://www.abeeolica.org. br/noticias/brasil-chega-a-marca-de-10-gw-de-energia-eolica-em-capacidade-instalada/. Acesso em: 08 de dez. 2016.

ANDRADE, H. D.; OLIVEIRA, A. F. F.; OLIVEIRA PINTO, M. Panorama do mercado eólico brasileiro - análise de investidores e fabricantes. Revista Brasileira de Energia, v. 20, no $^{\circ}, 2014$.

AMARANTE, O. A; BROWER, M.; ZACK, J.; EOLICA, C. S. E. Atlas do potencial eólico brasileiro. Brasília: MME; Rio de Janeiro: Eletrobrás, 2013. Disponível em: Acesso em: 29 nov. 2016. 
BASILIO, A. L. Entenda o horário de veráo. 2017. Disponível em: <http://fgvenergia. fgv.br/noticias/entenda-o-horario-de-verao>. Acesso em: 04 mar. 2018.

BEAN, P; BLAZQUEZ, J; NEZAMUDDIN, N. Assessing the cost of renewable energy policy options-A Spanish wind case study. Renewable energy, v. 103, p. 180-186, 2017.

BEZERRA, F. D; SANTOS, L. S. Potencialidades da Energia Eólica no Nordeste.

Caderno Setorial ETENE, Banco do Nordeste, 2, no 5, 2017.

BNDES. Banco Nacional do Desenvolvimento. Disponível em: https://www.bndes.gov. br/wps/portal/site/home/financiamento/produto/leiloes-infraestrutura/leilao-de-energianova-a4-a6-2017. Acesso em: 05 de março de 2018.

Banco Nacional do Desenvolvimento. Fundo Clima: energias renováveis.

Disponível em: https://www.bndes.gov.br/wps/portal/site/home/financiamento/produto/ fundo-clima-energias-renovaveis. Acesso em: 05 de março de 2018.

BRASIL. Lei no 9.991, de 24 de julho de 2000. Dispóe Sobre Realização de Investimentos em Pesquisa e Desenvolvimento e em Eficiência Energética Por Parte das Empresas Concessionárias, Permissionárias e Autorizadas do Setor de Energia Elétrica, e Dá Outras Providências. Brasília, 2000.

. Lei no 10.848, de 15 de março de 2004. Dispóe Sobre A Comercializaçáo de Energia Elétrica, Altera As Leis nos 5.655, de 20 de Maio de 1971, 8.631, de 4 de Março de 1993, 9.074, de 7 de Julho de 1995, 9.427, de 26 de Dezembro de 1996, 9.478, de 6 de Agosto de 1997, 9.648, de 27 de Maio de 1998, 9.991, de 24 de Julho de 2000, 10.438, de 26 de Abril de 2002, e Dá Outras Providências. Brasília, 2004a.

Decreto no 5.025, de 30 de março de 2004. Texto Compilado Regulamenta O Inciso I e Os $\$ \$ 1$ 1o, 2o, 3o, 40 e 50 do Art. $3 o$ da Lei no 10.438, de 26 de Abril de 2002, no Que Dispóem Sobre O Programa de Incentivo às Fontes Alternativas de Energia Elétrica - Proinfa, Primeira Etapa, e Dá Outras Providências. Brasília, 2004b.

. Ministério de Minas e Energia. Plano Nacional de Mineração 2030: Geologia, Mineração e Transformação Mineral. 2. ed. Brasília: MME, 2011. 178 p.

CARNEIRO, M. G.; CEQUEIRA, B. D. Participação da Geração Eólica em Leilóes de Energia e sua Contribuição em Tempos de Crise Energética. Revista Brasileira de Energias Renováveis, Curitiba, v. 5, p.51-64, 2016.

CASTRO, Nivalde José et al. Consideraçóes sobre as Perspectivas da Matriz Elétrica Brasileira. Pesquisa realizada pelo GESEL - Grupo de Estudos do Setor Elétrico junto com o Instituto de Economia da Universidade Federal do Rio de Janeiro. Textos de Discussão do Setor Elétrico No 19, Rio de Janeiro, 2010. Disponível em: http://www. gesel.ie.ufrj.br/app/webroot/files/publications/44_TDSE19.pdf. Acesso em: 11 Set 2016. 
CASTRO, Rui M. G. Energias Renováveis e Produção Descentralizada: introdução à energia eólica. Universidade Técnica de Lisboa. 2007. Disponível em: http://enerp4.ist. utl.pt/RuiCastro/download/Eolica_ed4.pdf. Acesso em: 21 Set. 2016.

\section{CONSELHO DE AVALIAÇÃO ECOSSISTÊMICA DO MILÊNIO. Ecossistemas e} bem-estar humano: estrutura para uma avaliação. São Paulo: Editora Senac, 2005 (p.61146)

DINCER, I, ROSEN, M. A. Energy: energy, environment and sustainable development. Elsevier, 2. ed. 2013.

DUTRA, Ricardo Marques. Viabilidade Técnico-Econômica da Energia Eólica Face ao Novo Marco Regulatório do Setor Elétrico Brasileiro. 2001. 309 p. Dissertação (mestrado em Planejamento Energético). Universidade Federal do Rio de Janeiro-COPPE, Rio de Janeiro, 2001.

Propostas de Políticas Específicas para Energia Eólica no Brasil após a Primeira fase do Proinfa, 2007. 437 f. Tese (Doutorado) - Curso de Engenharia do Departamento de Ciências em Planejamento Energético da Universidade Federal do Rio de Janeiro (UFRJ), Rio de janeiro, 2007.

DUTRA, R. M., SZKLO, A. S., 2006, "A Energia Eólica no Brasil: Proinfa e o Novo Modelo do Setor Elétrico". In: Anais do XI Congresso Brasileiro de Energia - CBE, 2006, Volume II, p. 842-868, Rio de Janeiro.

ELETROBRÁS. Programa de Incentivos a Fontes Alternativas de Energia PROINFA. Disponível em: < http://eletrobras.com/pt/Paginas/Proinfa.aspx> Acesso em: 10 de dezembro de 2016.

EMPRESA DE PESQUISA ENERGÉTICA - EPE. Plano Decenal de Expansáo da Malha de Transporte Dutoviário: PEMAT 2022. Brasília: MME, 2014. 294 p.

MME, 2016.

Balanço Energético Nacional: Relatório Síntese - ano base 2015. Brasília:

FRATE, Claudio Albuquerque. Políticas públicas para energias renováveis: fator de competitividade para eletricidade eólica e Siderurgia semi-integrada. 2006. 80 p. Dissertação (Mestrado em Política e Gestão Ambiental). Universidade de Brasília, Brasília, 2006.

GAVINO, Natália Azevedo. Energia Eólica: uma análise dos incentivos à produçáo (2002-2009). Instituto de Economia da Universidade Federal do Rio de Janeiro, Rio de Janeiro, 2011.

GONZÁLEZ, J. S.; LACAL-ARÁNTEGUI, R.. A review of regulatory framework for wind energy in European Union countries: current state and expected developments.

Renewable and Sustainable Energy Reviews, v. 56, p. 588-602, 2016. 
GWEC: GLOBAL WIND ENERGY COUNCIL. Global Wind Report. Annual Market Update, 2014. Disponível em: <http://www.gwec.net/wp-content/uploads/2015/03/ GWEC_Global_Wind_2014_Report_LR.pdf>. Acesso em: 25 set. 2016.

. Global Wind Report. Annual Market Update, 2015. Disponível em: http://www.gwec.net/wp-content/uploads/vip/GWEC-Global-Wind-2015-Report_ April-2016_22_04.pdf. Acesso em: 10 out. 2016.

INTERNATIONAL ENERGY AGENCY (IEA). 2015. World Energy Outlook, 2015. Paris, France.

MACEDO. Luziene Dantas. Produção de Energia Elétrica por Fonte Eólica no Brasil e Aspectos de seu Impacto na Regiáo Nordeste e Rio Grande do Norte. Tese (Doutorado) - Programa de Pós Graduação em Desenvolvimento Econômico da Universidade Estadual de Campinas, São Paulo (SP), 2015. Disponível em: http://www. bibliotecadigital.unicamp.br/document/?code=000949591. Acesso em: 15 de out. 2016

ÖZKAYNAK, B., ADAMAN, F., DEVINE, P. The identity of ecological economics: retrospects and prospects. Cambridge Journal of Economics. 36, p. 1123-1142, 2012.

PROGRAMA PROINFA. Disponível em <http://www.mme.gov.br/programas/proinfa/>

\section{OLIVEIRA NETO. C. R. ENERGIA EÓLICA E DESENVOLVIMENTO NO}

TERCEIRO MILÊNIO: reflexôes a partir do Brasil, Nordeste e Rio Grande do Norte. Dissertação de Mestrado do Programa de Pós Graduação em Economia da Universidade Federal do Rio Grande do Norte, 2016.

RINGER, N, J. Desafios do setor de energia eólica no Brasil: uma abordagem sistêmica. 2014. Tese de Doutorado. Universidade de São Paulo. Disponível em: < http:// www.teses.usp.br/teses/disponiveis/96/96132/tde-18072014-101417/en.php>

SACHS, Ignacy. A revolução energética do século XX. Estudos Avançados, USP, 19, n.55, p. 197-214, 06/2005. USP, 21, n. 59, p. 21-38 2007.

SANTOS, I. F. S.; FILHO, G. L. T.; BARROS, R. M. Análises econômicas, de sensibilidade e elasticidade em projetos de energias renováveis no Brasil. Revista Brasileira de Energia, v. 21, no 2, 2015.

STAHEL, Andri Werner. Capitalismo e entropia: os aspectos ideológicos de uma contradição e a busca de alternativas sustentáveis. In CAVALCANTI, C (ORG)

Desenvolvimento e natureza: estudos para uma sociedade sustentável.

UNEP (United Nations Environment Programme). Decoupling: natural resource use and environmental impacts from economic growth. 2011. Disponível em http://www. unep.org/resourcepanel/decoupling/files/pdf/decoupling_report_english.pdf Acesso em: 10 de dez de 2016. 